\title{
Controls on the vertical distribution of meiobenthos in mud: field and flume studies with juvenile fish*
}

\author{
Bruce C. Coull ${ }^{1}$, Margaret A. Palmer ${ }^{2}$, Philip E. Myers ${ }^{1}$ \\ ${ }^{1}$ Belle W. Baruch Institute for Marine Biology and Coastal Research, Marine Science Program and Department of Biology, \\ University of South Carolina, Columbia, South Carolina 29208, USA \\ ${ }^{2}$ Department of Zoology, University of Maryland, College Park, Maryland 20742, USA
}

\begin{abstract}
We investigated the influence of the bottom-feeding fish Leiostomus xanthurus Lacépède on the vertical microdistribution of meiobenthos. Sectioned cores which were taken at low tide in the field did not exhibit evidence that fish, which had foraged 3 to 4 h earlier, affected the vertical distribution of meiofauna. However, field cores collected where fish were feeding did show reductions in meiofaunal abundances in the top $2 \mathrm{~mm}$ of sediment. Controlled flume experiments also showed that fish influenced the vertical distribution of meiofauna. For copepods, copepod nauplii and foraminiferans, reductions in abundances occurred in the top $4 \mathrm{~mm}$ of sediments due to fish consumption and/or migration into the water. For nematodes, reductions in the top $2 \mathrm{~mm}$ occurred due to mortality (but not necessarily consumption by fish), as well as possible migration deeper into the sediments when fish were present. In conjunction with this study, we examined the possibility that estimates of total abundance of meiofauna may be influenced by the process of sectioning the cores. We found that total meiofauna abundance was significantly greater in sectioned than in non-sectioned cores, suggesting that investigators must test the effects of sample handling when choosing enumeration methods.
\end{abstract}

\section{INTRODUCTION}

The vertical distribution of meiobenthos in sediments has traditionally been characterized by taking sections of sediment at centimeter depth intervals. Only a few studies have examined fine-scale sections of a millimeter or two. For sand-dwelling meiofauna, Boaden \& Platt (1971) and Joint et al. (1982) studied the fine-scale vertical distribution in the field as it relates to the tidal cycle. For mud-dwelling meiofauna, Palmer \& Molloy (1986) studied the fine-scale vertical distribution in the presence and absence of flow using a laboratory flume. Reise (1979) and Fitzhugh \& Fleeger (1985) suggested that $\mathrm{crab}$ and fish predators may influence the vertical distribution of meiofauna; however, they did not section cores at fine-scale intervals.

As part of a study on the effects of juvenile fish predators on the meiofauna of muddy sediments, we wanted to determine if changes in the fine-scale verti-

\footnotetext{
- Contribution No. 752 from the Belle W. Baruch Institute for Marine Biology and Coastal Research
}

cal distribution of the meiofauna were related to fish foraging. We hypothesized that the activities of bottomfeeding fish, which consume meiofauna and also disturb the sediment as they feed, influence the spatial microdistribution of meiofauna within the sediments. In our study we used juvenile spot Leiostomus xanthurus Lacépède as fish predator. This fish feeds almost exclusively in muds (Smith \& Coull 1987) by taking bites out of the sediment and leaving feeding pits 2 to $3 \mathrm{~mm}$ deep (Billheimer \& Coull 1988). Juvenile spot ingest large numbers of meiofauna (Smith \& Coull 1987) and also cause loss of meiofauna through sediment disturbance effects (Palmer 1988a).

We initially examined the fine-scale vertical distribution of meiofauna in the field at low tide during 2 times of the year: in winter, when juvenile spot were not in the estuaries (January 1987) and in spring, when they were abundant (May 1987). The results of a separate study done shortly after this, suggested that alterations in the spatial distribution and abundance of meiofauna in response to feeding activities of juvenile spot are obliterated within $1.5 \mathrm{~h}$ (Billheimer \& Coull 1988). 
Thus, sampling, as we did, at low tide ( 3 to $4 \mathrm{~h}$ after fish had fed), was not an appropriate time to look for microspatial responses. We, therefore, analyzed data independently collected from a laboratory flume experiment designed to examine the vertical distribution of meiofauna in the presence/absence of fish. Experimental conditions in the flume were carefully controlled so that the only factor known to vary was the presence of fish. This experiment allowed us to examine the vertical distribution of meiofauna within the sediment, as well as the total number of meiofauna (all sections combined) when fish were present vs absent. This was important because changes in the vertical distribution of meiofauna may be due both to losses from surface sediments when fish predators are present and to vertical migration within the sediment.

Finally, we vertically sectioned additional field cores in May 1988 which were taken at mid-tide when fish were abundant and feeding. We combine the results of the field and flume studies to test the hypothesis that fish predators influence the vertical microdistribution of mud-dwelling meiofauna.

To fully analyze our data it was necessary to determine if abundance estimates from sectioned cores were comparable to those from non-sectioned cores. Thus, during all field sampling times, non-sectioned cores were collected in addition to sectioned cores. While the non-sectioned core data do not affect the hypothesis testing presented, the somewhat surprising results merit inclusion.

\section{MATERIALS AND METHODS}

Field study. The study site, a mid-intertidal, unvegetated mudflat (32 to $42 \mathrm{~m}$ median grain diameter) at Oyster Landing in the North Inlet estuarine system, Georgetown, South Carolina $\left(33^{\circ} 19.0^{\prime} \mathrm{N}, 79^{\circ} 11.6^{\prime} \mathrm{E}\right)$ was sampled on 13 and 14 January 1987, and on 25 and 26 May 1987 at low tide. The same site was sampled on 12 and 13 May 1988 when it was covered with $15 \mathrm{~cm}$ of water. On each day, 8 or 9 replicate samples were taken with a $1.8 \mathrm{~cm}$ diameter core tube $(4.50 \mathrm{~cm}$ long) to a depth of $3 \mathrm{~cm}$. The visible redox potential discontinuity layer was located at 20 to $22 \mathrm{~mm}$ in January and 9 to $10 \mathrm{~mm}$ in May 1987 and May 1988.

Upon removal from the sediment, 6 cores from each day were immediately placed on a moving micrometer plunger (a cork placed on the digital micrometer apparatus of a Gilson respirometer) and extruded in 1mm (January, May 1987), or in 2-mm (May 1988) intervals. Each interval (to $20 \mathrm{~mm}$ ) was sliced off with a razor blade and placed in a separate container with 10\% buffered formalin and Rose Bengal. The deepest 2 to $3 \mathrm{~cm}$ interval was not sectioned but extruded intact. Thus for January and May 1987, each core was divided into 21 sections, a section for each $\mathrm{mm}$ interval to $20 \mathrm{~mm}$, i.e. 0 to 1,1 to 2,2 to $3 \mathrm{~mm}$, etc. and the section below $20 \mathrm{~mm}$. In May 1988, each core yielded $11 \mathrm{sec}-$ tions, i.e. 0 to 2,2 to $4 \ldots, 18$ to $20 \mathrm{~mm}$ and the section below $20 \mathrm{~mm}$. To make all the field data and the flume data comparable, the January and May 1987 meio-

Table 1 Mean field abundance per $10 \mathrm{~cm}^{2}(\mathrm{SE})$ per vertical section of the 4 most abundant meiofaunal taxa

\begin{tabular}{|c|c|c|c|c|c|c|c|c|c|c|c|c|}
\hline $\begin{array}{l}\text { Section } \\
(\mathrm{mm})\end{array}$ & \multicolumn{3}{|c|}{ Nematoda } & \multicolumn{3}{|c|}{ Copepoda } & & Nauplii & $\%$ & $\begin{array}{c}\text { Foram } \\
\text { No. }\end{array}$ & $\begin{array}{l}\text { nifera } \\
( \pm \mathrm{SE})\end{array}$ & $\%$ \\
\hline \multicolumn{13}{|l|}{$\operatorname{Jan} 1987$} \\
\hline $0-2$ & 802 & $(86)$ & 22.5 & 29 & (5) & 34.5 & 78 & $(14)$ & 61.9 & 127 & $(28)$ & 26.0 \\
\hline $3-4$ & 734 & (42) & 20.6 & 25 & (4) & 29.8 & 34 & (5) & 27.0 & 77 & (11) & 15.8 \\
\hline $5-6$ & 499 & (24) & 14.0 & 14 & (2) & 16.7 & 7 & (2) & 5.6 & 53 & (7) & 10.9 \\
\hline $7-8$ & 346 & $(26)$ & 9.7 & 6 & (2) & 7.1 & 2 & (1) & 16 & 41 & (5) & 8.4 \\
\hline $9-10$ & 265 & (21) & 7.4 & 4 & (1) & 4.8 & 1 & (1) & 0.8 & 30 & (6) & 6.1 \\
\hline$>10$ & 916 & $(97)$ & 25.7 & 6 & (3) & 7.1 & 4 & (3) & 3.2 & 160 & $(41)$ & 32.8 \\
\hline \multicolumn{13}{|c|}{ May 1987} \\
\hline $0-2$ & 735 & $(115)$ & 28.7 & 44 & (8) & 34.5 & 73 & $(17)$ & 49.6 & 102 & (26) & 40.9 \\
\hline $3-4$ & 331 & $(38)$ & 12.9 & 12 & (2) & 29.8 & 18 & (5) & 12.2 & 34 & (6) & 13.6 \\
\hline $5-6$ & 218 & $(17)$ & 8.5 & 10 & (4) & 14.1 & 12 & (3) & 8.2 & 34 & (11) & 13.6 \\
\hline $7-8$ & 207 & (31) & 8.1 & 1 & (1) & 1.4 & 5 & (1) & 3.4 & 17 & (3) & 6.8 \\
\hline $9-10$ & 164 & (21) & 6.4 & 1 & (1) & 1.4 & 10 & (2) & 6.8 & 11 & (3) & 4.4 \\
\hline$>10$ & 909 & $(131)$ & 35.4 & 3 & (2) & 4.2 & 29 & (13) & 19.7 & 51 & (19) & 20.5 \\
\hline \multicolumn{13}{|c|}{ May 1988} \\
\hline $0-2$ & 36 & $(6)$ & 3.3 & 15 & (4) & 23.1 & 31 & (4) & 24.2 & 131 & (25) & 33.2 \\
\hline $3-4$ & 127 & (17) & 11.7 & 18 & (3) & 27.7 & 48 & $(10)$ & 37.5 & 105 & (19) & 26.6 \\
\hline $5-6$ & 158 & (23) & 14.5 & 18 & (4) & 27.7 & 22 & (5) & 17.2 & 61 & (10) & 15.4 \\
\hline $7-8$ & 145 & $(20)$ & 13.3 & 5 & (1) & 7.7 & 11 & (2) & 8.6 & 30 & (5) & 7.8 \\
\hline $9-10$ & 122 & (13) & 11.2 & 3 & (1) & 4.6 & 5 & (1) & 3.9 & 23 & (5) & 5.8 \\
\hline$>10$ & 559 & (48) & 46.0 & 6 & (1) & 9.2 & 11 & (2) & 8.6 & 45 & (7) & 11.2 \\
\hline
\end{tabular}




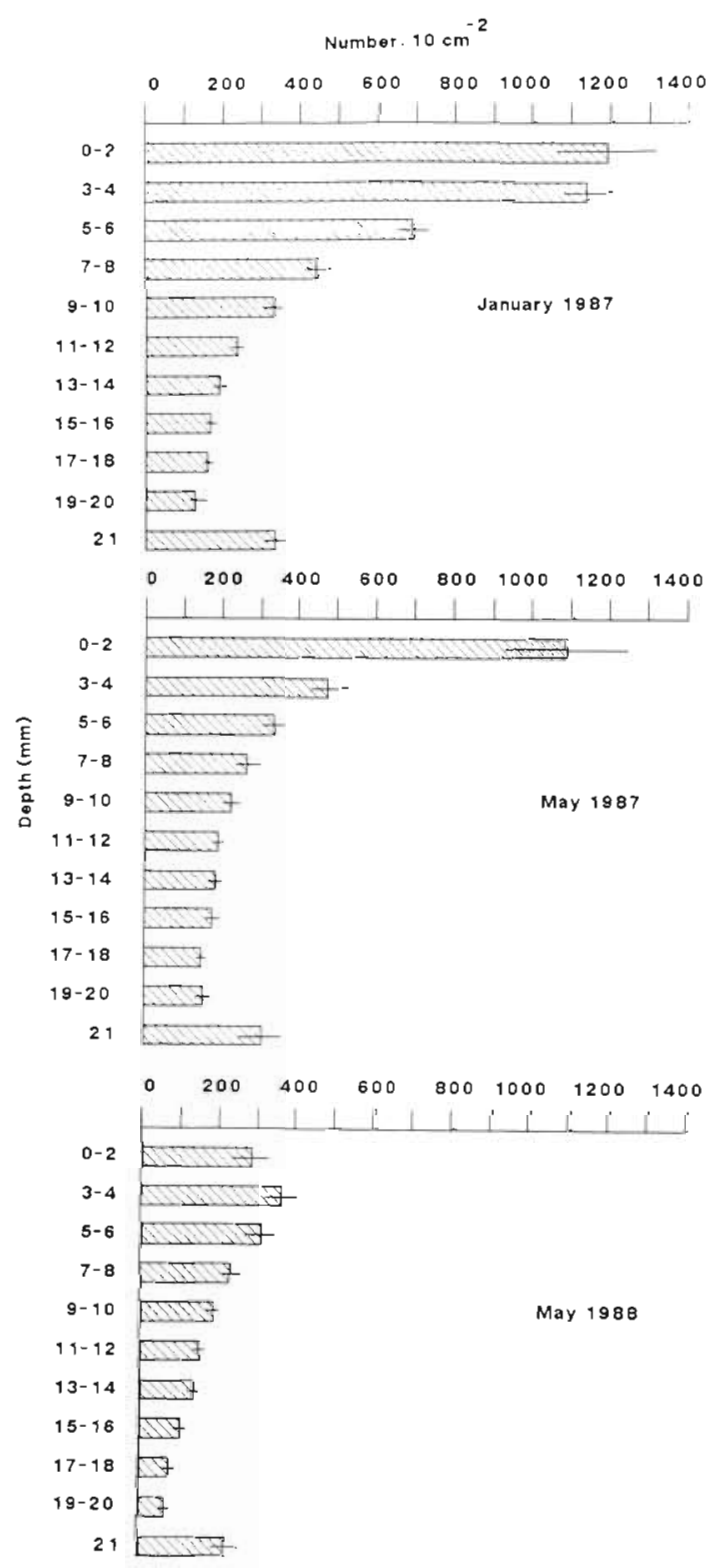

Fig. 1 Vertical distribution of the total meiofauna in Jan 1987, May 1987 and May 1988 from field samples. Standard error lines shown

fauna counts from the individual $\mathrm{mm}$ sections were combined into $2 \mathrm{~mm}$ intervals. All data then were analyzed based on the number of individuals in $2 \mathrm{~mm}$ sections. The 2 to 3 additional cores collected each day were not sectioned. These 'control cores' were sorted in their entirety in order to assess whether or not total core abundance was influenced by vertical sectioning. All sediment samples were sieved through $63 \mu \mathrm{m}$ mesh by washing the sediment with tap water. Each sample was washed from the sieve into counting trays and the meiofauna were enumerated to major taxon and copepods to species.
The 3 field data sets were analyzed separately by the General Linear Model (GLM) procedure of SAS (SAS Institute 1985) on data that were $\log _{10}(n+1)$ transformed to meet the assumptions of normality. Analyses were conducted separately for each sampling month because there were significant abundance differences (1-way ANOVA, abundance vs month; $p=0.0001$ to 0.0002 depending on taxon) between months and we knew, a priori, that faunal abundance and species were different seasonally and between years (Coull 1985, Coull \& Dudley 1985). Flume data were analyzed by using $t$-tests to determine if abundance varied between predator and no predator treatments.

Flume study. Laboratory flume experiments were performed in a wetlab located $200 \mathrm{~m}$ from the field site described above. The experimental design consisted of 2 treatments, one in which predators were allowed to forage on meiofauna contained in flume box cores for $10 \mathrm{~h}$ and one in which box cores were held in the flume for $10 \mathrm{~h}$ but not exposed to predators. Ten replicate box cores were used per treatment.

The stratigraphically undisturbed sediment box cores $(20 \times 20 \mathrm{~cm}$ cross section, $15 \mathrm{~cm}$ deep) were collected during low tide just after the mudflat was exposed. The cores were allowed to equilibrate overnight in the flume which had been slowly filled with water. The plexiglass flume $-2.4 \mathrm{~m}$ long, $20 \mathrm{~cm}$ wide, and $15 \mathrm{~cm}$ deep - is described in detail in Palmer (1986). Box cores were placed in the flume such that the sediment surface was flush with the bottom of the flume. A mesh-covered partition ( $1 \mathrm{~cm}^{2}$ mesh openings) was placed $10 \mathrm{~cm}$ upstream of the box core and $10 \mathrm{~cm}$ downstream of the box core to confine fish to the test section. Mean flow was measured with an electromagnetic current meter and was well below the critical erosion velocity for sediments (Palmer \& Gust 1985). Water depth was maintained at $10 \mathrm{~cm}$, and mean flow was $1 \mathrm{~cm} \mathrm{~s}^{-1}$ which prevented stagnation and ensured high oxygen levels.

We used 25 juvenile spot $(30$ to $50 \mathrm{~mm}$ standard length) in each predator test. Palmer (1988a) provides the rationale for the fish densities used and the length of the experimental manipulation as well as observations that fish feeding and behavior was unaffected by the laboratory procedures. The fish were collected $24 \mathrm{~h}$ earlier and left unfed in equilibration tanks prior to each test. All tests were completed during daylight; however, flume walls and top were covered with dark plastic to avoid disturbing the fish during experiments. In the field juvenile spot feed regardless of light conditions and appear to feed primarily on a rising or at high tide (Archambault 1987). At the end of each test, a core (1.8 $\mathrm{cm}$ diam.) was taken to a depth of $15 \mathrm{~mm}$ from within each box core. Cores were sectioned in $2 \mathrm{~mm}$ intervals to a depth of $10 \mathrm{~mm}$, and the last $5 \mathrm{~mm}$ were preserved in 
Table 2. Total numbers of meiofauna per $10 \mathrm{~cm}^{2}$ enumerated in vertically sectioned field cores (V), non-sectioned (control) field cores (C), and flume cores from predator (P) and no predator (NP) treatments. Numbers are means, standard errors are in parentheses

\begin{tabular}{|c|c|c|c|c|c|c|c|}
\hline Date & Core type & $\mathrm{n}$ & Total meiofauna & Nematodes & Copepods & Copepod nauplii & Forams \\
\hline Jan 87 & $\begin{array}{l}C \\
\text { V }\end{array}$ & $\begin{array}{r}4 \\
12\end{array}$ & $\begin{array}{l}2448(182) \\
4988(234)\end{array}$ & $\begin{array}{l}1870(159) \\
3562(136)\end{array}$ & $\begin{array}{l}63(10) \\
84(11)\end{array}$ & $\begin{array}{l}111(21) \\
127(20)\end{array}$ & $\begin{array}{rr}94 & (19) \\
488 & (234)\end{array}$ \\
\hline May 87 & $\begin{array}{l}C \\
V\end{array}$ & $\begin{array}{r}6 \\
12\end{array}$ & $\begin{array}{l}1675(346) \\
3541(177)\end{array}$ & $\begin{array}{l}1296(237) \\
2564(185)\end{array}$ & $\begin{array}{l}31(16) \\
71(11)\end{array}$ & $\begin{array}{r}66(30) \\
147(25)\end{array}$ & $\begin{array}{rr}73 & (31) \\
249 & (38)\end{array}$ \\
\hline May 88 & $\begin{array}{l}\mathrm{C} \\
\mathrm{V}\end{array}$ & $\begin{array}{r}6 \\
12\end{array}$ & $\begin{array}{l}1136(180) \\
2115(147)\end{array}$ & $\begin{array}{rr}636 & (54) \\
1147 & (90)\end{array}$ & $\begin{array}{ll}36 & (7) \\
65 & (8)\end{array}$ & $\begin{array}{rr}55 & (8) \\
128 & (17)\end{array}$ & $\begin{array}{l}248 \text { (127) } \\
395 \quad(39)\end{array}$ \\
\hline Flume & $\begin{array}{l}\mathrm{NP} \\
\mathrm{P}\end{array}$ & $\begin{array}{l}10 \\
10\end{array}$ & $\begin{array}{l}3046(335) \\
2689(221)\end{array}$ & $\begin{array}{l}2522(113) \\
2234(181)\end{array}$ & $\begin{array}{l}63(14) \\
17 \quad(8)\end{array}$ & $\begin{array}{l}84(14) \\
28(14)\end{array}$ & $\begin{array}{ll}174 & (63) \\
121 & (67)\end{array}$ \\
\hline
\end{tabular}

their entirely. Core sections were preserved in Rose Bengal/formalin for later faunal enumeration.

\section{RESULTS}

Three-way ANOVA labundance of a taxon or copepod species as a function of day, core, and section nested within a core) indicated that there were no differences in field abundance of a taxon or species between days within a month (e.g. the two January 1987 days). Since days were not different from each other during any month, the $2 \mathrm{~d}$ within each of the 3 mo were combined for the separate analyses discussed below.

In 1987, when field samples were collected at low tide, there were significantly more total meiofauna in January than in May $1987(p<0.05)$; however, maximum abundance of meiofauna was in the top $2 \mathrm{~mm}$ on both dates (Table 1, Fig, 1). This pattern was true for total meiofauna, as well as nematodes, copepods, and foraminiferans (Table 1).

In the flume study, water cover was always present and, for the predator treatments, samples were collected just after fish had foraged. A significant reduction in the total number (all vertical sections combined) of copepods $(p<0.01)$, nauplii $(p<0.01)$, and foraminiferans $(p<0.01)$ was found when fish were present (Table 2). These lower abundances were due almost entirely to reductions in the top $4 \mathrm{~mm}$ of the sediments (Fig. 2). The total number of nematodes did not vary between predator and no predator flume treatments; however, the number within the top $2 \mathrm{~mm}$ was significantly lower in predator vs no predator treatments $(p<0.001)$.

In the final field sampling in May 1988, when cores were collected at mid tide as fish foraged, the abundance of fauna was reduced near the sediment surface compared to the January and May 1987 data (Fig. 1, Table 1). In May 1988 the maximum abundance of meiofauna was between 3 and $6 \mathrm{~mm}$ (Fig. 1, Table 1).
Throughout the field study, 10 copepod species were encountered and 4 species - Nannopus palustris Brady, Stenhelia (D.) bifidia Coull, Enhydrosoma propinquum (Brady), Diarthrodes aegideus (Brian) - comprised $89 \%$ of all copepods. While the patterns of vertical distribution were not entirely consistent between sampling dates and the abundance of a species varied between months, there were some general trends in the species vertical microdistribution. For the most part $S$. (D.) bifidia and E. propinquum reached maximum abundance below $2 \mathrm{~mm}$, whereas $D$. aegideus, when present, was most abundant in the surface $2 \mathrm{~mm}$ and $N$. palustris in the upper $4 \mathrm{~mm}$ (Fig. 3).

Comparison of non-sectioned (control) cores with vertically sectioned cores showed that in all 3 mo there were significantly more meiofauna in the sectioned cores (all sections combined) than in the non-sectioned control cores $(p<0.001)$. For each taxon and date, except copepods and their nauplii in January 1987 , there were significantly more individuals in the sectioned cores than control cores $(p<0.05$; Table 2$)$.

\section{DISCUSSION}

When the samples were collected at low tide in 1987 , there was no evidence that microspatial vertical distribution differed when fish were absent (January) vs present (May) (Fig. 1). Since we now know that meiofauna recolonize spot feeding pits within $1.5 \mathrm{~h}$ (Billheimer \& Coull 1988), we would not expect to find microspatial responses of the meiofauna to foraging fish if we sampled at low tide ( 3 to $4 \mathrm{~h}$ after fish had foraged). The results of the present study confirmed this. The flume studies tested for such a response on a more appropriate time scale and we found evidence that juvenile spot did alter the vertical distribution of meiofauna.

Fitzhugh \& Fleeger (1985) suggested that nematodes migrated deeper into sediments when gobiid fish fed. These fish feed in a manner similar to juvenile spot, i.e. 
by disturbing the bottom as they take bites from the sediment surface. In the present study we have some evidence that nematodes vertically migrated when fish fed; however, the evidence is not unambiguous. Because the total number of meiofauna in all sediment sections combined was not statistically reduced (Table 2) but the number in the surface sediments was reduced in the predator flume treatments (Fig. 2), it would follow logically that the fauna vertically migrated deeper into the sediments in response to the activities of the fish. However, there was only a small increase in the number of nematodes in deeper sediment layers (4 to $15 \mathrm{~mm}$ ) for the predator treatments (Fig. 2). Thus, we conclude that the decreased abundances of nematodes near the surface when fish fed were due to mortality and, to a lesser extent, due to vertical migrations. The morality was probably not due to consumption by the fish but resulted from disturbance effects due to the feeding activities of the fish; this effect is known to be quite pronounced for nematodes (Palmer 1988a).

In the flume study, predator-related reductions in abundances of copepods, nauplii, and foraminiferans were almost entirely limited to the top $4 \mathrm{~mm}$ (Fig. 2).
There is no evidence that these fauna vertically migrated deeper into the sediments when fish were present. Thus, the predators probably altered the vertical microdistribution through consumption of these meiofauna in the surface sediments. Although one would expect that predator-avoidance behaviors by copepods would be highly selected for, migration down into the sediment may not be a suitable behavior. Unlike nematodes which generally reside deeper in the sediments than other meiofauna, many of the copepods are epibenthic, known to reside in the uppermost layers of the sediments and may rely on the sedimentwater interface for resources (Decho \& Fleeger 1988, Palmer 1988b). The copepods may possess other predator avoidance behaviors which include darting actions or even swimming into the water (Vinyard 1980). Indeed, some of the predator-associated decreases in abundance of copepods in these experiments may have been due to copepod entry into the water rather than consumption by fish (Palmer 1988a).

Decreased abundances of meiofauna in the surface sediments were found in the final field samples taken in May 1988 when water cover was present and juvenile

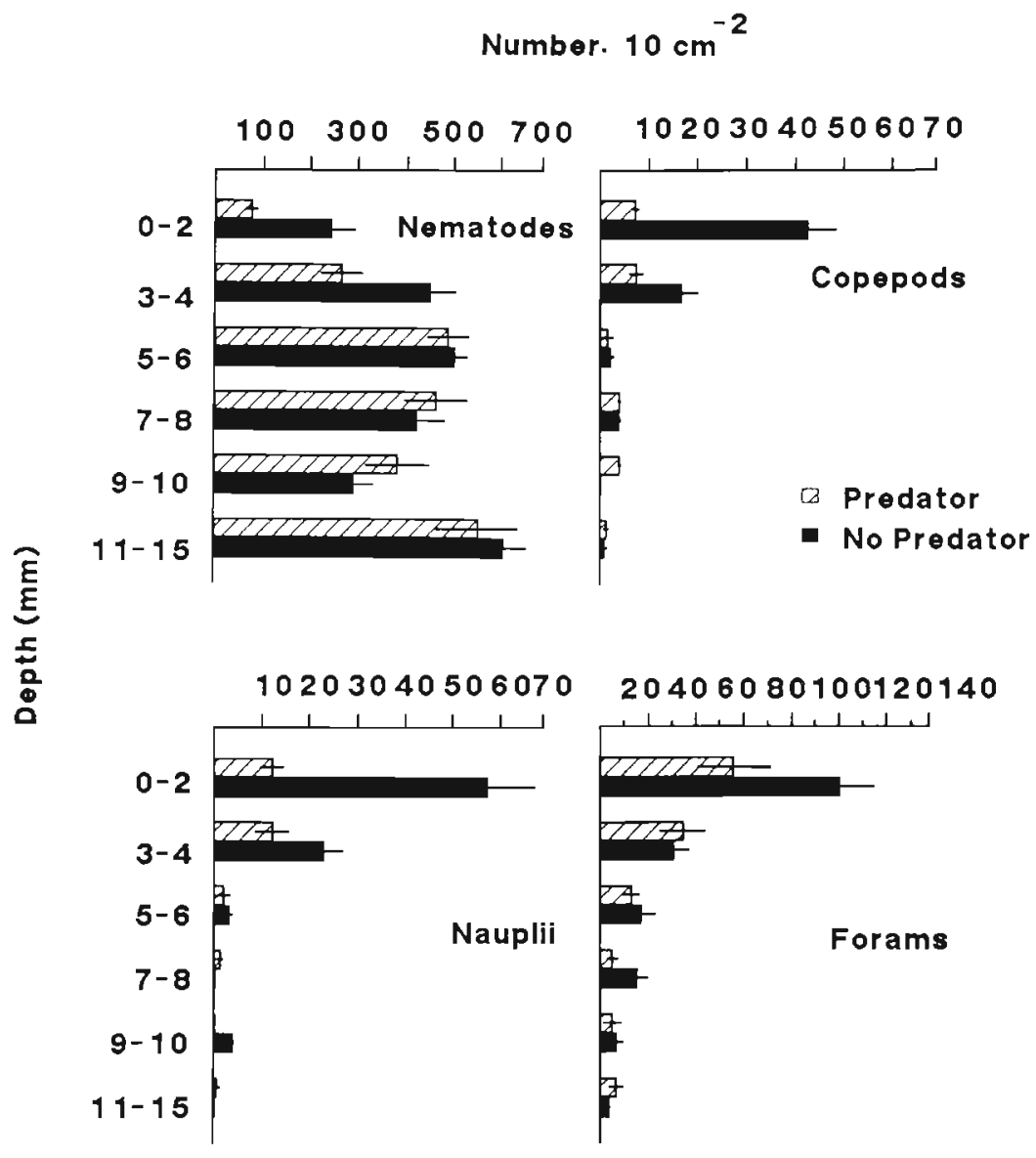

Fig. 2. Abundance and vertical distribution of taxa from the flume study with and without fish predators. Standard error lines shown 


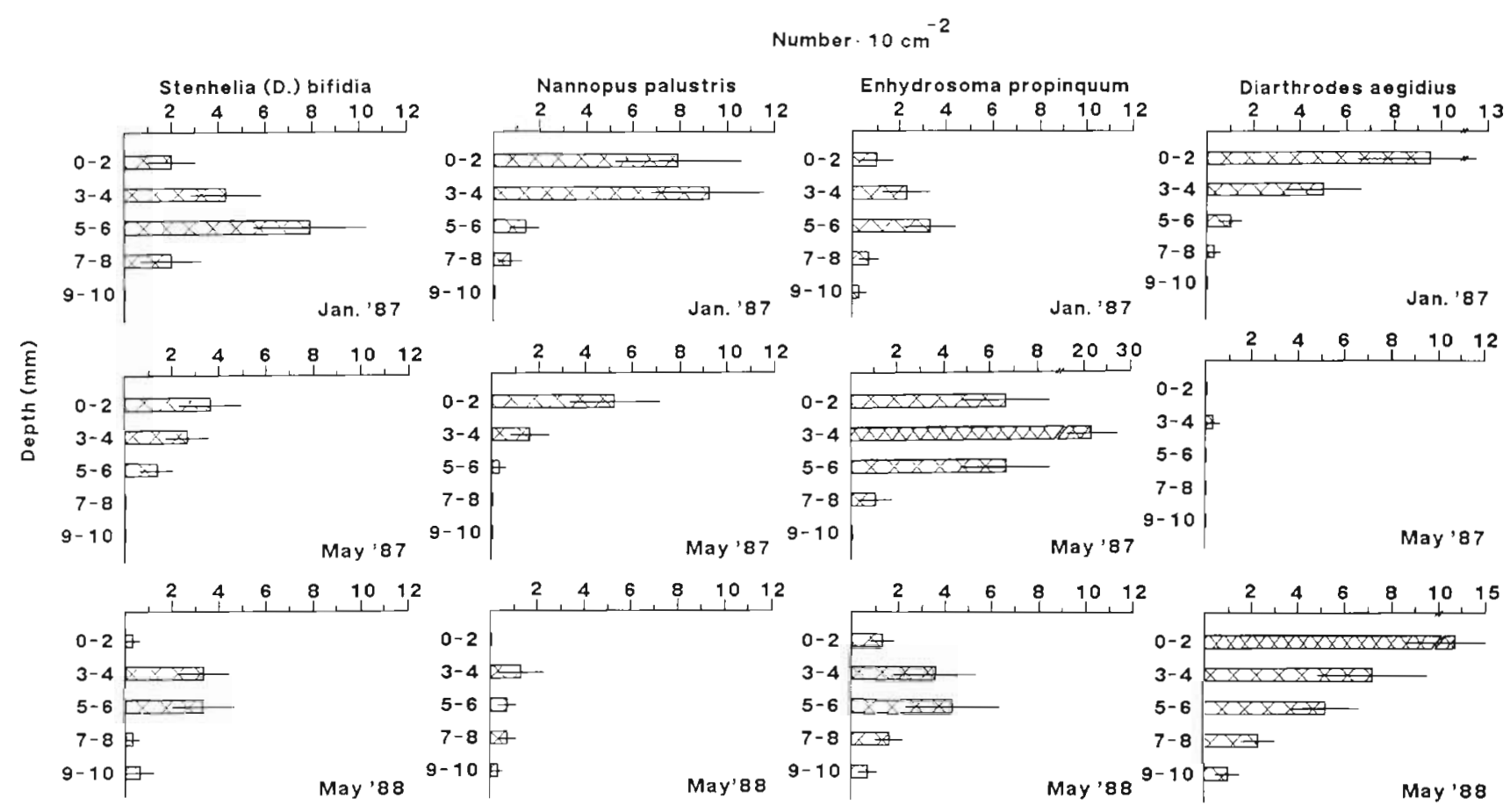

Fig. 3. Vertical distribution of the 4 dominant harpacticoid copepods in Jan 1987, May 1987 and May 1988 from field samples. Standard error lines shown

spot were actively feeding. This further supports the conclusion from the flume experiment that the fish do alter vertical microdistribution by causing a reduction in the abundance of meiofauna in the upper few $\mathrm{mm}$. The different results found from the 1987 field data vs the flume data and 1988 field data suggest that such microspatial alterations are short term (disappear by low tide).

The vertical distribution of the copepods indicates which species should be available for predators and is consistent with predation patterns observed in our other studies. Ellis \& Coull (1989) found that Enhydrosoma propinquum was unaffected by juvenile spot predation. E. propinquum is most abundant deeper in the sediment (Fig. 3). Diarthrodes aegideus and Nannopus palustris are 2 of the most common species found in juvenile spot guts (Coull \& Feller unpubl.) and they occur most abundantly near the surface (Fig. 3). Stenhelia (D.) bifidia irregularly occurs in the fish guts and this too is probably a result of its vertical distribution.

That we counted significantly more meiofauna in our vertically sectioned cores than in the non-sectioned (control) cores (Table 2) is disturbing. A priori, we expected the abundance estimates to be similar, since a difference (as we found) would indicate a sample processing effect. Since we did not change sorters and the results were consistent over all 3 sampling dates, the difference must be due to sample processing. We suspect there are 2 potential causes of the differences. Firstly, the non-sectioned cores contain much more sediment 'per sample' than the 1 or $2 \mathrm{~mm}$ section samples and were washed much more vigorously and longer than the sectioned samples. Were some fauna washed through the $63 \mu \mathrm{m}$ sieve? Secondly, a nonsectioned 'sample' with its greater amount of sediment was more difficult to look through and possibly the fauna were not as easily seen, thus resulting in lower counting efficiency Whatever the reason, it is clear that the vertically sectioned samples gave significantly higher values. Interestingly, Rutledge \& Fleeger (1988) recently reported that estimates of meiofaunal abundances were higher when smaller cores are used. Thus, it appears that if all the meiofauna are to be counted, smaller amounts of sediment may allow for more complete counting and identification

By combining field and laboratory flume results, we conclude: (1) vertical microdistribution of meiofauna was altered by fish feeding; (2) when fish are present, reductions in the abundances of copepods, nauplii, and foraminiferans in the top few $\mathrm{mm}$ of sediment were due to losses from consumption or emigration while nematode reductions were due to mortality associated with fish predation/disturbance and, possibly a migration downward in the sediments; (3) species and taxa that occupy the upper few $\mathrm{mm}$ will more likely find their way into a sediment biting predator's stomach than those which occur deeper; (4) the amount of sediment collected by coring may effect sorting efficiency and bias estimates of meiofaunal abundance. 
Acknowledgements. We thank DrR. J. Feller, B. W. Dudley, L. E. Billheimer and M. J. Ellis for assistance in the field; B.W. Dudley, L. E. Billhemmer, M. Carl and C. Schultheis for assistance in sorting samples; $T$. Donelan for the computer graphics. Drs G. T Chandler, R. J. Feller and R. M. Warwick made constructive comments on earlier drafts of this manuscript. This research was supported by the Biological Oceanography Program of the National Science Foundation, NSF Grant OCE-8521345 (B. C. Coull \& R. J. Feller, principal investigators) and NSF Grant OCE8509904 (M. A. Palmer, principal investigator).

\section{LITERATURE CITED}

Archambault, J. A. (1987). Temporal patterns in gut fullness of juvenile spot, Leiostomus xanthurus, in North Inlet, South Carolina. M.S. thesis, University of South Carolina, Columbia

Billheimer, L. E., Coull, B. C. (1988). Bioturbation and recolonization of meiobenthos in juvenile spot (Pisces) feeding pits. Estuar. coast. Shelf Sci. 27: 335-340

Boaden, P. J. S., Platt, H. M. (1971). Daily migration patterns in an intertidal meiobenthic community. Thalassia jugosl. 7 : $1-12$

Coull, B. C. (1985). Long-term variability of estuarine meiobenthos: an 11 year study. Mar Ecol. Prog. Ser 24: 205-218

Coull, B. C., Dudley, B. W. (1985). Dynamics of meiobenthic copepod populations: a long-term study (1973-1983). Mar. Ecol. Prog. Ser. 24: 219-229

Decho, A. W., Fleeger, J. W. (1988). Microscale dispersion of meiobenthic copepods in response to food-resource patchiness. J. exp. mar. Biol. Ecol. 118: 229-243

Ellis, M. J., Coull, B. C. (1989). Fish predation on meiobenthos: field experiments with juvenile spot (Leiostomus xanthurus). J. exp. mar. Biol. Ecol. (in press)

Fitzhugh, G. R., Fleeger, J. W. (1985). Goby (Pisces: Gobiidae)

This article was submitted to the editor interactions with meiofauna and small macrofauna. Bull. mar. Sci. 36: 436-444

Joint, I. R., Gee, J. M., Warwick, R. M. (1982). Determination of fine-scale vertical distribution of microbes and meiofauna in an intertidal sediment. Mar Biol. 72 : $157-164$

Palmer, M. A. (1986). Hydrodynamics and structure: interactive effects on meiofauna dispersal. J. exp. mar Biol. Ecol. 104: 53-68

Palmer, M. A. (1988a). Epibenthic predators and marine meiofauna: separating predation, disturbance, and hydrodynamic effects. Ecology 69: 1251-1259

Palmer, M. A. (1988b). Dispersal of marine meiofauna: a review and conceptual model explaining passive transport and active emergence with implications for recruitment. Mar. Ecol. Prog. Ser. 48: 81-91

Palmer, M. A., Gust, G. (1985). Dispersal of meiofauna in a turbulent tidal creek. J. mar. Res. 43: 179-210

Palmer, M. A., Molloy, R. M. (1986). Water flow and the vertical distribution of meiofauna: a flume experiment. Estuaries 9: 225-228

Reise, K. (1979). Moderate predation on meiofauna by the macrobenthos of the Wadden Sea. Helgoländer wiss. Meeresunters. 32: 453-465

Rutledge, P. A., Fleeger, J. W. (1988). Laboratory studies on core sampling with application to subtidal meiobenthos collection. Limnol. Oceanogr. 33: 274-280

SAS Institute (1985). SAS User's Guide: statistics, Version 5 edn. SAS Institute, Inc., Cary, North Carolina

Smith, L. D., Coull, B. C. (1987). Juvenile spot (Pisces) and grass shrimp predation on meiobenthos in muddy and sandy substrata. J. exp. mar. Biol. Ecol. 105: 123-136

Vinyard, G. L. (1980). Differential prey vulnerability and predator selectivity: effects of evasive prey on bluegill (Lepomis macrochirus) and pumpkinseed ( $L$. gibbosus) predation. Can. J. Fish. Aquat. Sci. 37: 2294-2299

Manuscript first received: January 24, 1989

Revised version accepted: May 5, 1989 